illness. It is difficult to understand why they recommend the treatment of antipsychotic induced hyperprolactinaemia with the addition of either of these drugs to conventional antipsychotics rather than changing to clozapine. We feel that treatment with clozapine should be considered as an alternative to this polypharmacy, and we are concerned that Duncan and Taylor's review did not mention this option.

Jann, M. W., Gramsley, S. R. Gray, E. C., et al (1993) Pharmacokinetics and pharmacodynamics of clozapine. Clinical Pharmacoktnetics, 24, 161-176.

MELTZER, H. Y. \& FANG, V. S. (1976) Serum prolactin levels in schizophrenia - effect of antipsychotic drugs: a preliminary report. In Hormones, Behavior and Psychopathology (ed. E. J. Sachar), pp. 178-191. New York: Raven Press.

G. W. MerCer and A. H. Young

School of Neurosciences,

University of Newcastle,

Division of Psychiatry.

The Royal Victoria Infirmary,

Newcastle upon Tyne NE1 4LP

Sir: In our article, we noted that clozapine was the only antipsychotic not to cause hyperprolactinaemia. Clozapine may therefore successfully be used in patients with neuroleptic-induced hyperprolactinaemia. This fact was only implied in our article and we agree with your correspondents that the option to use clozapine should have been more explicit. In addition, as your correspondents state, clozapine is licensed to be used where patients are intolerant of standard neuroleptics for any reason.

In practice, we always suggest clozapine to prescribers as one of several possible therapeutic gambits in hyperprolactinaemia. In our unit, clinicians prefer to try dose reduction or amantadine. As far as we are aware, none of over 100 patients taking clozapine in our unit were prescribed the drug because of previous problems with hyperprolactinaemia.

D. DUNCAN and D. TAYLOR

The Maudsley Hospital, Denmark Hill, London SE5 $8 A Z$

\section{The use of new antipsychotics}

Sir: We read with interest Professor Kerwin's article on the use of new antipsychotic drugs such as clozapine (Psychiatric Bulletin, January 1996, 20, 23-29). He argued that "enthusiasm for the use of new antipsychotics has not been as great as one might expect" and attributes this, partly, to cost. We wish to contribute to the debate by discussing further the issue of cost.
The total adult population of our catchment area is approximately 203878. Assuming the point prevalence of schizophrenia to be between 2.5 to 5.3 per 1000 , the number of expected patients with schizophrenia in our community would be between 509 and 1080 . Of these 152324 would be treatment resistant (Kane et al, 1988). If the estimated cost of clozapine per annum is $£ 2500$, the likely cost to our service of prescribing clozapine to all patients who theoretically could benefit from it would be $\$ 380000$ 810000 . This upper figure is twice our annual drug budget.

Furthermore, at present, the cost to our service of prescribing clozapine is approximately $\$ 175355$ per annum. This is $36 \%$ of the total drug budget and amounts to about $54 \%$ of the sum expended on antipsychotic drugs. To put it in another way, $36 \%$ of the whole budget is spent on 56 patients who amount to less than $1 \%$ of patient contacts in one year.

The issue of cost-effectiveness of clozapine must be conducted within the context of actual budgets and of opportunity costs. We mean by this that there are competing claims upon a limited budget and that the needs of other patients and the flxed costs of institutions must be included in the cost-benefit analysis of clozapine. This is particularly true in services which no longer contain large groups of chronically ill patients within long-stay wards. The gains which would have been made in being able to secure discharges to community facilities are not evident in such settings. And, if there are already facilities for intensive follow-up and treatment at home, the cost benefits of reduced admissions would be negligible.

In conclusion, we believe that a thorough costbenefit analysis of the use of clozapine in the UK context is now urgently needed.

KANE, J., Honigfeid, G., Singer, J., et al (Clozarll Collaborative Study Group) (1988) Clozapine for the treatment resistant schizophrenic: a double blind comparison with chlorpromazine. Archives of General Psychiatry. 45, 789-796.

S. SHAH and F. OYebode

The Queen Elizabeth Psychiatric Hospital, Edgbaston, Birmingham B15 $29 Z$

\section{Competence consent and dementia}

Sir: The articles by Bartlett (Psychiatric Bulletin, November 1996, 19, 670-672) and Burns \& Harris (Psychiatric Bulletin, February 1996, 20, 107-108) help to clarify our ethical responsibilities to patients with dementia. However, competence, consent and dementia remain a dilemma.

When I set up a research project involving home visits to elderly people with dementia I had to 
consider the validity of consent. I was surprised, and relieved, that the Local Ethics Committee did not address this complicated issue.

I am confident my research does no harm but I do not consider it to be in the best interest of the patient. I consequently rely on varying levels of consent. First, verbal consent is obtained by the consultant psychogeriatrician selecting the patients at initial assessment, but however openended the request it must feel compelling to agree. Second, I write prior to visits, giving an outline of my role and project, request for a meeting, suggested date and estimate of the time we will need. I confirm confidentiality will be respected and, whatever decision is made, will not compromise future management. My home telephone number is included.

On meeting I explain again and read a brief consent form. Usually this is willingly signed. Occasionally I receive a 'proxy consent' by a relative or warden not empowered to do sol Sometimes conditions are stipulated by the carer, usually that she remains in the room. Interestingly, relattves often encourage me to 'entertain' the elderly person, and those who remain are often delighted by 'pockets of retained knowledge and insight'.

Despite these safeguards, I rely at a personal level on good faith. The willingness to be accepted and welcomed into a home and the initial agreement for me to interview them is critical. Often, when I leave, the person is unable to recollect my name, occupation or reason for being there.

I am not convinced my consent is valid but implied consent and mutual good will are vital for continued research and interest in elderly people with dementia.

\section{K. HOFBERG \\ Uffculme Clinic, Queensbridge Road, Moseley. Birmingham, B13 8QD}

\section{Substance misuse in medium secure units}

Sir: In my experience of working in a medium secure unit I was struck by the widespread consumption of alcohol and illegal drugs. It was virtually impossible to control the entry of drugs and education or other treatment programmes systematically failed. However unethical it may seem I believe there was a positive aspect to it. A large proportion of forensic patients misuse drugs and/or alcohol and it would be natve to expect them not to continue to do so following discharge into the community. In a drug-free environment we would be missing an essential aspect of the assessment, namely, the effect that alcohol or drugs have on the mental state of patients with a long history of substance misuse. In these patients the positive effect of psychiatric medication may be suppressed by alcohol or drugs and it is important that prior to discharge we are aware of this.

\section{J. MYLONAKIS \\ Rydon House, Cheddon Road, Taunton TA2 7AZ}

\section{Falls in the elderly}

Sir: We performed an audit of falls on an assessment ward for the organically mentally ill. The risk factors for falls and strategies for their prevention have been well researched (Myers et al, 1991; Rubenstein et al, 1994).

Using the incident report forms from the ward for 1994 and 1995 we looked retrospectively at the circumstances of 95 falls over a 21 month period. There were four main circumstances in which patients were likely to fall: while walking $21 \%$, while getting onto or off a chair/lavatory seat $20 \%$, falling out of bed/at night $19 \%$ and unknown $19 \%$.

Forty-one per cent of falls occurred while staff were observing patients (walking or sitting), when two fractures occurred. Being seen to fall makes it more likely that a fall will be reported but we felt that this was an area which could be improved upon. We had expected to find that most patients would have fallen at night or while unobserved during the day, which would be a function of the ward layout and staffing levels.

We hope that by alerting staff on the ward that patients are as likely to fall while they are observing them as when they are not that the incidence of falls can be reduced.

MYERS, A. H., et al (1991) Risk factors assoclated with falls and injuries among elderly institutionalized persons. American Journal of Epidemiology. 133, 1179-1190.

RUBENSTEIN, L. Z., JOSEPHSON, K. R. \& ROBBINS, A. S. (1994) Falls in the nursing home. Annals of Internal Medictne. 121, 442-451.

S. KHALAF and C. MORRIS

Ridgewood Centre, Old Bisley Road, Frimley. Camberley. Surrey GU16 5QE

\section{Medical members of Mental Health Review Tribunals}

Sir: Concern has been expressed by some of our psychiatrist members who are medical members of Mental Health Review Tribunals (MHRTs) as to their position regarding any allegations or claims made against them arising from preliminary psychiatric examinations prior to tribunal hearings.

When sitting in a judicial capacity psychiatrists are of course immune from suit as regards their 